\title{
Design and Implementation of Synchronization-free TDOA Localization System Based on UWB
}

\author{
Wei WANG ${ }^{1,2}$, Junjie $H U A N G^{2}$, Shaobin CAI ${ }^{1}$, Junjie $Y A N G^{2}$ \\ ${ }^{1}$ College of Computer Science and Technology, HuaQiao University, No.668, Jimei Street, Xiamen,361021,China \\ ${ }^{2}$ College of Automation, Harbin Engineering University, No.145, Nantong Street, Harbin, 150001, China
}

chinaww2006@126.com, huangjunjie291@hrbeu.edu.cn

Submitted September 4, 2018 / Accepted December 2, 2018

\begin{abstract}
At present, indoor localization system based on ultra-wideband (UWB) has attracted more and more attention. In UWB system, Time Difference of Arrival (TDOA) and Two-Way Ranging (TWR) are widely used. However, TDOA requires high-accuracy time synchronization between all anchor nodes and even slight noise can cause large localization error. In TWR, although two-way communication between anchor nodes with known location and blind nodes to be located can avoid the time synchronization issue effectively, the clock drift and the number of blind nodes will affect the system performance. To overcome these problems, a new synchronization-free TDOA location algorithm is proposed. Firstly, the clock model is established and the influence of antenna delay is considered. Then, the system signal exchange mechanism and localization model are proposed. In the system, the blind nodes just receive the ranging signals from anchor nodes so that the system has no limit on the number of blind nodes. Finally, the major factor affecting the accuracy of ranging - clock drift, is discussed, and then a clock frequency offset compensation algorithm is proposed. The indoor localization experiment results show that the indoor localization system designed in this paper can achieve 3-D localization.
\end{abstract}

\section{Keywords}

Indoor localization, Two-Way Ranging (TWR), Time Difference of Arrival (TDOA), time synchronization

\section{Introduction}

At present, the location-based service (LBS) in the indoor environment is of great importance in many applications [1], [2]. Common solutions used for indoor localization include Zigbee [3], RFID [4], WiFi [5], Bluetooth [6], indoor landmark reference system [7] and UWB [8]. Compared to other solutions, UWB can provide the fine time resolution and have the ability to resist multi-path interference [9], [10]. So the indoor localization system based on UWB can usually provide higher localization accuracy than other methods [11].
There are many methods for positioning, such as Received Signal Strength (RSS), Angle of Arrival (AOA), Time of Arrival (TOA), Time Difference of Arrival (TDOA), TwoWay Ranging (TWR). RSS has limited accuracy due to the difficulty in precisely modelling the relationship between the received signal strength and the actual distance [12]. In some positioning scenes, such as large shopping malls and hospitals, the accuracy provided by RSS can meet the requirements of personnel positioning, but may not satisfy the requirement of precise positioning in the robot room. AOA is not suitable for UWB because a large number of signal paths [13]. TOA requires high-accuracy time synchronization for all the nodes [14], which is difficult to achieve in practice. TDOA and TWR are the most popular methods in UWB system. In normal TDOA localization scheme, the location of the blind node can be estimated by calculating the distance difference between anchor nodes and blind node [15]. So TDOA requires high-accuracy time synchronization between all anchor nodes. To solve time synchronization issue, a synchronization-free TDOA scheme (called Whistle) in [16] is proposed to achieve high time resolution and acquire the positioning accuracy of 10-20 cm, but blind nodes are required to transmit signal. J. X. Lee, et al. [17] proposed a new method that does not require the time synchronization initially and can realize sub-meters ranging error. The Sequential-TDOA method in [18] is proposed to reduce the requirement of time synchronization, but the clock drift is not considered and the positioning accuracy is nearly $1 \mathrm{~m}$. In [19], the clock offset is estimated by symmetrical doublesided two way ranging (SDS-TWR) but used as a constant value. TWR, also called Round Trip Time (RTT) [20], can avoid the time synchronization issue effectively with twoway communication between anchor nodes and blind nodes. However, TWR is hard to maintain signal exchange if the system contains many blind nodes, so it not flexible and has the limit on the number of users.

To solve the above issues, a new synchronization-free TDOA localization scheme is proposed. Firstly, the clock system is modelled with starting time and clock frequency, the time synchronization can be achieved in the algorithm. Then, in order to eliminate the difference of starting time of 
all nodes, two-way communication is adopted to design the signals exchange. Unlike normal TWR, the blind nodes in this system are passive and just receive the ranging signals from anchor nodes, so that the system can break the limit on the number of users. What's more, Kalman Filter algorithm is applied to compensate the relative clock drift between the blind node and the master station. Finally, the localization experiments verified the effectiveness and feasibility of the proposed scheme.

This paper is organized as follows. In Sec. 2, the clock model is established and the influence of antenna delay is considered. Based on this, the ranging model is determined. In Sec. 3, one of the major factors affecting the accuracy of ranging - clock drift, is discussed, and then a method of clock frequency offset compensation is introduced. In Sec. 4, some experiments are carried out to prove the feasibility and positioning accuracy of the scheme. Finally, conclusions are drawn in Sec. 5.

\section{The Localization Principle}

\subsection{The Clock Model}

In the localization system, each node has a set of clock system which is independent of each other. The continuous and homogeneous reference time can be chosen as the system clock to establish a unified clock system for time synchronization. The clock of nodes is one-to-one correspondence with the reference time, and we can model the relationship between clock frequency and reference time of nodes. Take the node ${ }_{i}$ for example. Assume that the starting time and the clock frequency of node ${ }_{i}$ are $\bar{t}_{\text {start }^{\text {node }}}$ and $\lambda_{\text {node }_{i}}(t)$ respectively. For clock frequency $\lambda_{\text {node }_{i}}(t)$, it is used to convert the reference time into local time in numerical terms. In this paper, DW1000 is used in the system. DW1000 is a fully integrated low power, single chip CMOS radio transceiver IC compliant with the IEEE 802.15.4-2011 ultra-wideband (UWB) standard. It spans $6 \mathrm{RF}$ bands from $3.5 \mathrm{GHz}$ to $6.5 \mathrm{GHz}$ and facilitates proximity detection to an accuracy of $+/-10 \mathrm{~cm}$ using two-way ranging time-of-flight measurements [21]. The sampling frequency of DW1000 is about $64 \mathrm{GHz}$, then $\lambda_{\text {node }_{i}}(t)=6.4 \times 10^{10}$, so one second (reference time) corresponds to the local time value is $6.4 \times 10^{10}$. The relationship between the local time of node ${ }_{i}$ and the reference time can be expressed as

$$
t^{\text {node }_{i}}=\int_{\bar{t}_{\text {start }_{i}}}^{\bar{t}_{\text {node }_{i}}} \lambda_{\text {node }_{i}}(t) \mathrm{d} t .
$$

In (1), $t^{\text {node }_{i}}$ is the local time of node $i$ and $\bar{t}^{\text {node }_{i}}$ is the reference time corresponding to $t^{\text {node }_{i}}$. It is worth mentioning that the clock frequency is a constant value, but there will be drift due to temperature variation.

The process of transmitting signal is shown in the Fig. 1. The time from the signal generating unit to the antenna is the transmission signal delay and designated as $\Delta t_{\mathrm{S}}^{\text {node }_{i}}$.
It is known from the DW1000 chip manual "IC CalibrationAntenna Delay" section [21] that such delays need to be handled in order to measure the distance accurately. Suppose that node $_{i}$ transmits a ranging signal and the transmitting time stamp is $t_{\mathrm{DS}}^{\text {node }_{i}}$. After some time delay, the signal leaves the antenna at $t_{\mathrm{TS}}^{\text {node }_{i}} . \bar{t}_{\mathrm{DS}}^{\text {node }_{i}}$ and $\bar{t}_{\mathrm{TS}}^{\text {node }_{i}}$ are the references time corresponding to $t_{\mathrm{DS}}^{\mathrm{node}_{i}}$ and $t_{\mathrm{TS}}^{\mathrm{node}_{i}}$. The time delay can be expressed as

$$
\bar{t}_{\mathrm{TS}}^{\text {node }_{i}}-\bar{t}_{\mathrm{DS}}^{\text {node }_{i}}=\Delta t_{\mathrm{S}}^{\text {node }_{i}}+\varepsilon_{\mathrm{S}}^{\text {node }_{i}} .
$$

In (2), $\Delta t_{\mathrm{S}}^{\text {node }_{i}}$ is a constant and represents the transmit time delay of node $i . \varepsilon_{\mathrm{S}}^{\text {node }_{i}}$ is the noise with zero mean. Then, the transmitting time stamp can be expressed as

$$
\begin{aligned}
& t_{\mathrm{DS}}^{\mathrm{node}_{i}}=\int_{\bar{t}_{\mathrm{start}}^{\mathrm{node}_{i}}}^{\bar{t}_{\mathrm{DS}^{\mathrm{node}}}} \lambda_{\text {node }_{i}}(t) \mathrm{d} t \\
& =\int_{\bar{t}_{\mathrm{start}^{-}}}^{\bar{t}_{\mathrm{TS}^{-}}^{\mathrm{node}_{i}}-\Delta t_{\mathrm{S}}^{\text {node }_{i}}-\varepsilon_{\mathrm{S}}^{\text {node }_{i}}} \lambda_{\text {node }_{i}}(t) \mathrm{d} t .
\end{aligned}
$$

The process of receiving signal is shown in the Fig. 2. Similar to the transmission process described above. Suppose that a signal arrives at the antenna of node $i_{i}$ at $t_{\mathrm{TR}}^{\text {node }_{i}}$. After some time delay, the node ${ }_{i}$ receives the signal and the receiving time stamp is $t_{\mathrm{DR}}^{\mathrm{node}_{i}} . \bar{t}_{\mathrm{DR}}^{\text {node }_{i}}$ and $\bar{t}_{\mathrm{TR}}^{\text {node }_{i}}$ are the references time corresponding to $t_{\mathrm{DR}}^{\text {node }_{i}}$ and $t_{\mathrm{TR}}^{\mathrm{node}_{i}}$. The time delay can be expressed as

$$
\bar{t}_{\mathrm{DR}}^{\text {node }_{i}}-\bar{t}_{\mathrm{TR}}^{\text {node }_{i}}=\Delta t_{\mathrm{R}}^{\text {node }_{i}}+\varepsilon_{\mathrm{R}}^{\text {node }_{i}} .
$$

In (4), $\Delta t_{\mathrm{R}}^{\text {node }_{i}}$ is a constant and represents the receive time delay of node ${ }_{i} . \varepsilon_{\mathrm{R}}^{\text {node }_{i}}$ is the noise with zero mean. The receiving time stamp can be expressed as

$$
\begin{aligned}
& t_{\mathrm{DR}}^{\text {node }_{i}}=\int_{\bar{t}_{\text {start }_{i}}}^{\bar{t}_{\mathrm{DR}^{\text {node }_{i}}}^{\text {node }_{i}}} \lambda_{\text {node }_{i}}(t) \mathrm{d} t \\
& =\int_{\bar{t}_{\mathrm{start}^{-}}^{\text {node }_{i}}}^{\bar{t}_{\mathrm{TR}}^{\mathrm{node}_{i}}+\Delta t_{\mathrm{R}}^{\text {node }_{i}}+\varepsilon_{\mathrm{R}}^{\text {node }_{i}}} \lambda_{\text {node }_{i}}(t) \mathrm{d} t .
\end{aligned}
$$

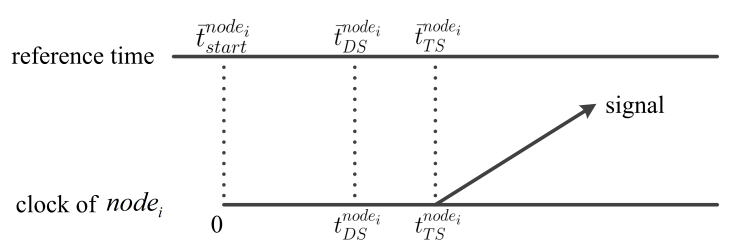

Fig. 1. The process of transmitting signal.

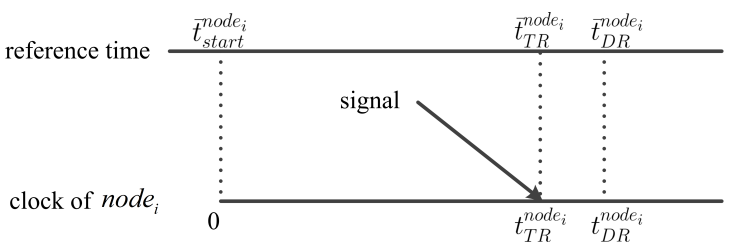

Fig. 2. The process of receiving signal. 


\subsection{The System Signal Exchange Mechanism}

The localization system contains a master station (MS), $L(L \geq 3)$ slave stations (SS), and $N(N>0)$ blind nodes (also called tags (T)). MS and SS are anchor nodes whose positions are known and fixed. They are transceivers. And blind nodes are receivers. MS coordinates the order of information transmission between nodes in the system. We call it a signal exchange mechanism. As is shown in Fig. 3, the system signal exchange mechanism is achieved by $L$ groups of signal exchange. First of all, MS transmits a ranging signal, and the slave station $1\left(\mathrm{SS}_{1}\right)$ and all the blind nodes receive this signal. After some time delay, $\left(\mathrm{SS}_{1}\right)$ transmits another ranging signal, $\mathrm{MS}$ and all the blind nodes receive this signal to complete the first group of signal exchange. The other groups are similar. The $L$ groups of signal exchange form a cycle of system signal exchange mechanism. In the system, the blind nodes just receive the ranging signal from MS and $\mathrm{SS}$ and never transmit signals. Therefore, the system can support unlimited blind nodes at the same time. What's more, the number of blind nodes does not affect the signal exchange between MS and SS. So the system is flexible and practical.

\subsection{The TDOA Localization Model}

In the system, the localization process of blind nodes is similar to each other. Take the blind node $j\left(T_{j}\right)$ for example to introduce the localization model. For convenience of representation, only one blind node location method will be discussed below, with the subscript $j$ omitted and denoted as T. All blind nodes are located in the same way and do not interfere with each other.The $i^{\text {th }}(i \leq L)$ group of signal exchange is shown in Fig. 4. In fact, a cycle of signal exchange mechanism is quite short, and the moving speed of blind node is generally slow. So we can consider that blind node is stationary in one cycle. Assume that $d_{\mathrm{MS}}^{\mathrm{SS}}, d_{\mathrm{MS}}^{\mathrm{T}}$ and $d_{\mathrm{SS}_{i}}^{\mathrm{T}}$ represent the distance from MS to $\mathrm{SS}_{i}$, from MS to T and from $\mathrm{SS}_{i}$ to T respectively. To facilitate reading, the symbol mark in Fig. 4 is hereby declared. Superscript denotes node, subscript D denotes information at signal processing unit, $\mathrm{T}$ denotes signal at antenna, $\mathrm{S}$ denotes transmission, and $\mathrm{R}$ denotes reception.

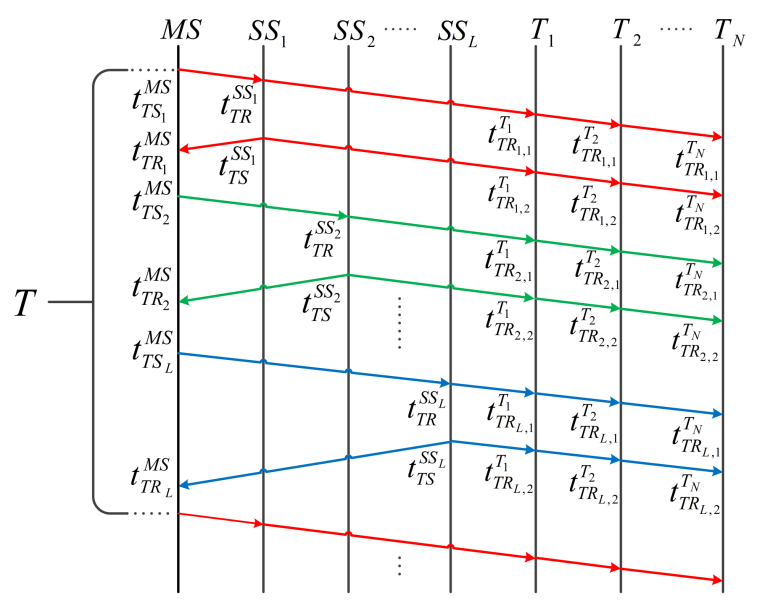

Fig. 3. The system signal exchange mechanism.

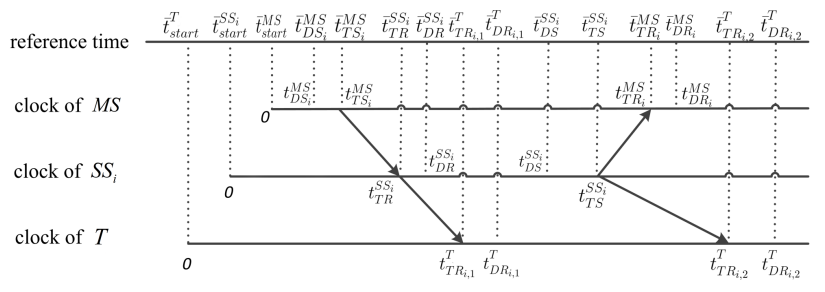

Fig. 4. The $i^{\text {th }}$ group of signal exchange.

For example, $t_{\mathrm{TR}_{i, 1}}^{\mathrm{T}}$ indicates the time when the received signal reaches the blind node antenna for the first time in $i^{\text {th }}$ group information exchange. Assume that $\mathrm{c}$ represents the light speed. According to TOA [14]

$$
\begin{aligned}
& \left\{\begin{aligned}
d_{\mathrm{MS}}^{\mathrm{T}} & =\mathrm{c}\left(\bar{t}_{\mathrm{TR}_{i, 1}}^{\mathrm{T}}-\bar{t}_{\mathrm{TS}_{i}}^{\mathrm{MSS}}\right) \\
d_{\mathrm{MS}}^{\mathrm{SS}_{i}} & =\mathrm{c}\left(\bar{t}_{T R_{i}}^{\mathrm{MS}_{1}}-\bar{t}_{\mathrm{TS}_{i}}^{\mathrm{SS}^{2}}\right) \\
d_{\mathrm{SS}_{i}}^{\mathrm{T}} & =\mathrm{c}\left(\bar{t}_{\mathrm{TR}_{i, 2}}^{\mathrm{T}}-\bar{t}_{\mathrm{TS}}^{\mathrm{SS}}\right)
\end{aligned}\right. \\
& d_{\mathrm{MS}}^{\mathrm{T}}-d_{\mathrm{SS}_{i}}^{\mathrm{T}} \\
& =\mathrm{c}\left(\bar{t}_{\mathrm{TR}_{i, 1}}^{\mathrm{T}}-\bar{t}_{\mathrm{TS}_{i}}^{\mathrm{MS}}\right)-\mathrm{c}\left(\bar{t}_{\mathrm{TR}_{i, 2}}^{\mathrm{T}}-\bar{t}_{\mathrm{TS}_{i}}^{\mathrm{SS}_{i}}\right) \\
& =\mathrm{c}\left(\bar{t}_{\mathrm{TR}_{i, 1}}^{\mathrm{T}}-\bar{t}_{\mathrm{TS}_{i}}^{\mathrm{MS}}\right)-\mathrm{c}\left(\bar{t}_{\mathrm{TR}_{i, 2}^{\mathrm{T}}}^{\mathrm{T}}-\bar{t}_{\mathrm{TS}}^{\mathrm{SS}_{i}}\right)+d_{\mathrm{MS}}^{\mathrm{SS}_{i}}-d_{\mathrm{MS}}^{\mathrm{SS}_{i}} \\
& =\mathrm{c}\left(\bar{t}_{\mathrm{TR}_{i, 1}}^{\mathrm{T}}-\bar{t}_{\mathrm{TS}_{i}}^{\mathrm{MS}}\right)-\mathrm{c}\left(\bar{t}_{\mathrm{TR}_{i, 2}}^{\mathrm{T}}-\bar{t}_{\mathrm{TS}^{\mathrm{SS}}}^{\mathrm{SS}_{i}}\right) \\
& +\mathrm{c}\left(\bar{t}_{\mathrm{TR}_{i}}^{\mathrm{MS}}-\bar{t}_{\mathrm{TS}}^{\mathrm{SS}_{i}}\right)-d_{\mathrm{MS}}^{\mathrm{SS}_{i}} \\
& =\mathrm{c}\left(\bar{t}_{\mathrm{TR}_{i}}^{\mathrm{MS}_{i}}-\bar{t}_{\mathrm{TS}_{i}}^{\mathrm{MS}}\right)-\mathrm{c}\left(\bar{t}_{\mathrm{TR}_{i, 2}}^{\mathrm{T}}-\bar{t}_{\mathrm{TR}_{i, 1}}^{\mathrm{T}}\right)-d_{\mathrm{MS}}^{\mathrm{SS}_{i}} \\
& \Rightarrow \\
& d_{\mathrm{MS}}^{\mathrm{T}}-d_{\mathrm{SS}_{i}}^{\mathrm{T}} \\
& =\mathrm{c}\left(\bar{t}_{\mathrm{DR}_{i}}^{\mathrm{MS}}-\bar{t}_{\mathrm{DS}_{i}}^{\mathrm{MS}}\right)-\mathrm{c}\left(\bar{t}_{\mathrm{DR}_{i, 2}}^{\mathrm{T}}-\bar{t}_{\mathrm{DR}_{i, 1}}^{\mathrm{T}}\right)-d_{\mathrm{MS}}^{\mathrm{SS}_{i}}-\Delta d+\eta_{i} \text {. }
\end{aligned}
$$

In formula (6)

$$
\left\{\begin{array}{l}
\Delta d=\mathrm{c}\left(\Delta t_{\mathrm{R}}^{\mathrm{MS}}+\Delta t_{\mathrm{S}}^{\mathrm{MS}}\right) \\
\eta_{i}=\mathrm{c}\left(\varepsilon_{\mathrm{R}_{i, 2}}^{\mathrm{T}}-\varepsilon_{\mathrm{R}_{i, 1}}^{\mathrm{T}}-\varepsilon_{\mathrm{R}_{i}}^{\mathrm{MS}}-\varepsilon_{\mathrm{S}_{i}}^{\mathrm{MS}}\right)
\end{array},\right.
$$

$\Delta d$ represents a distance constant caused by receiving time delay and transmitting time delay of MS. Wherein the values of $\Delta t_{\mathrm{R}}^{\mathrm{MS}}$ and $\Delta t_{\mathrm{S}}^{\mathrm{MS}}$ represent receive time delay and transmit time delay of MS, respectively. $\eta_{i}$ represents the Gauss white noise with zero mean.In the formula (6), $d_{\mathrm{MS}}^{\mathrm{SS}_{i}}$ is the distance from the master base station MS to the $i^{\text {th }}$ slave base station, and they are fixed at a known position and therefore are known quantities. However, $\left(\bar{t}_{\mathrm{DR}_{i}}^{\mathrm{MS}}-\bar{t}_{\mathrm{DS}_{i}}^{\mathrm{MS}}\right)$ can only be obtained from MS's clock, $\left(\bar{t}_{\mathrm{DR}_{i, 2}}^{\mathrm{T}}-\bar{t}_{\mathrm{DR}_{i, 1}}^{\mathrm{T}}\right)$ can only be obtained from T's clock, SS does not participate in the calculation, so there is no need for anchor node clock synchronization. According to Sec. 2.1, Fig. 4 can be expressed as 


$$
\begin{aligned}
& \left\{\begin{aligned}
t_{\mathrm{DS}}^{\mathrm{MS}} & =\int_{\bar{t}_{\mathrm{start}}}^{\overline{\mathrm{MS}}_{\mathrm{\textrm {MS }}}^{\mathrm{MS}}} \lambda_{\mathrm{MS}}(t) \mathrm{d} t \\
t_{\mathrm{DR}}^{\mathrm{MS}} & =\int_{\bar{t}_{\mathrm{start}}}^{\overline{\mathrm{MR}}_{i}} \lambda_{\mathrm{MS}}(t) \mathrm{d} t
\end{aligned}\right. \\
& \Rightarrow \\
& t_{\mathrm{DR}_{i}}^{\mathrm{MS}}-t_{\mathrm{DS}_{i}}^{\mathrm{MS}}=\int_{\bar{t}_{\mathrm{DS}_{i}}}^{\bar{t}_{\mathrm{DR}}^{\mathrm{MS}}} \lambda_{\mathrm{MS}}(t) \mathrm{d} t \\
& =\lambda_{\mathrm{MS}}\left(\xi_{i}^{\mathrm{MS}}\right)\left(\bar{t}_{\mathrm{DR}_{i}}^{\mathrm{MS}}-\bar{t}_{\mathrm{DS}_{i}}^{\mathrm{MS}}\right) \\
& \begin{array}{l}
\Rightarrow \\
\bar{t}_{\mathrm{DR}_{i}}^{\mathrm{MS}}-\bar{t}_{\mathrm{DS}_{i}}^{\mathrm{MS}}=\frac{t_{\mathrm{DR}_{i}}^{\mathrm{MS}}-t_{\mathrm{DS}_{i}}^{\mathrm{MS}}}{\lambda_{\mathrm{MS}}\left(\xi_{i}^{\mathrm{MS}}\right)},
\end{array} \\
& \left\{\begin{array}{c}
t_{\mathrm{DR}_{i, 1}}^{\mathrm{T}}=\int_{\bar{t}_{\mathrm{start}}^{\mathrm{T}}}^{\bar{t}_{\mathrm{DR}}^{\mathrm{T}}} \lambda_{\mathrm{T}}(t) \mathrm{d} t \\
t_{\mathrm{DR}_{i, 2}}^{\mathrm{T}}=\int_{\bar{t}_{\mathrm{start}}^{\mathrm{T}}}^{\bar{t}_{\mathrm{DR}_{i, 2}}^{\mathrm{T}}} \lambda_{\mathrm{T}}(t) \mathrm{d} t
\end{array}\right. \\
& t_{\mathrm{DR}_{i, 2}}^{\mathrm{T}}-t_{\mathrm{DR}_{i, 1}}^{\mathrm{T}}=\int_{\bar{t}_{\mathrm{DR}_{i}}}^{\bar{t}_{\mathrm{DR}_{i, 2}}^{\mathrm{T}}} \lambda_{\mathrm{T}}(t) \mathrm{d} t \\
& =\lambda_{\mathrm{T}}\left(\xi_{i}^{\mathrm{T}}\right)\left(\bar{t}_{\mathrm{DR}_{i, 2}}^{\mathrm{T}}-\bar{t}_{\mathrm{DR}_{i, 1}}^{\mathrm{T}}\right) \\
& \begin{array}{l}
\Rightarrow \\
\bar{t}_{\mathrm{DR}_{i, 2}}^{\mathrm{T}}-\bar{t}_{\mathrm{DR}_{i, 1}}^{\mathrm{T}}=\frac{t_{\mathrm{DR}_{i, 2}}^{\mathrm{T}}-t_{\mathrm{DR}_{i, 1}^{\mathrm{T}}}^{\mathrm{T}}}{\lambda_{\mathrm{T}}\left(\xi_{i}^{\mathrm{T}}\right)} .
\end{array}
\end{aligned}
$$

In (8) (9), $\xi_{i}^{\mathrm{MS}}$ and $\xi_{i}^{\mathrm{T}}$ represent a constant in the period of $\left(\bar{t}_{\mathrm{DS}_{i}}^{\mathrm{MS}}, \bar{t}_{\mathrm{DR}_{i}}^{\mathrm{MS}}\right)$ and $\left(\bar{t}_{\mathrm{DR}_{i, 1}}^{\mathrm{T}}, \bar{t}_{\mathrm{DR}_{i, 2}}^{\mathrm{T}}\right)$ respectively. In addition, a crystal oscillator of NX2016AB $-38.4 \mathrm{MHz}$ ST4 [22] is used in this system, the stability of the crystal oscillator is $20 \mathrm{ppm}$, and the time required for sub-cycle communication is about $8 \mathrm{~ms}$, so it can meet the requirements of the system clock stability. So in one cycle it can be assumed that $\lambda_{\mathrm{MS}}(t)$ is constant and the value inside the interval $\left(\bar{t}_{\mathrm{DS}_{i}}^{\mathrm{MS}}, \bar{t}_{\mathrm{DR}_{i}}^{\mathrm{MS}}\right)$ equals to $\lambda_{\mathrm{MS}}\left(\xi_{i}^{\mathrm{MS}}\right)$. Similarly, it can be assumed that $\lambda_{\mathrm{T}}(t)$ is constant and equals to $\lambda_{\mathrm{T}}\left(\xi_{i}^{\mathrm{T}}\right)$ between the interval $\left(\bar{t}_{\mathrm{DR}_{i, 1}^{\mathrm{T}}}^{\mathrm{T}}, \bar{t}_{\mathrm{DR}_{i, 2}^{\mathrm{T}}}^{\mathrm{T}}\right)$. $k^{\mathrm{MS}}\left(k^{\mathrm{MS}}=1 / \lambda_{\mathrm{MS}}\left(\xi_{i}^{\mathrm{MS}}\right)\right)$ and $k^{\mathrm{T}}\left(k^{\mathrm{T}}=1 / \lambda_{\mathrm{T}}\left(\xi_{i}^{\mathrm{T}}\right)\right)$ represent time resolution of MS and $T$ respectively in one cycle. According to (6), (8), (9)

$$
\begin{aligned}
& d_{\mathrm{MS}_{\mathrm{c}}^{\mathrm{T}}}^{\mathrm{T}}-d_{\mathrm{SS}_{i}}^{\mathrm{T}} \\
= & \frac{{ }_{\mathrm{MS}}}{\lambda_{\mathrm{MS}\left(\xi_{i}^{\mathrm{MS}}\right)}}\left(t_{\mathrm{DR}_{i}}^{\mathrm{MS}}-t_{\mathrm{DS}_{i}}^{\mathrm{MS}}\right)-\frac{{ }^{\mathrm{c}}}{\lambda_{\mathrm{T}}\left(\xi_{i}^{\mathrm{T}}\right)}\left(t_{\mathrm{DR}_{i, 2}}^{\mathrm{T}}-t_{\mathrm{DR}_{i, 1}}^{\mathrm{T}}\right) \\
& -d_{\mathrm{MS}}^{\mathrm{SS}}-\Delta d+\eta_{i} \\
= & \mathrm{c} k^{\mathrm{MS}} \Delta t_{i}^{\mathrm{MS}}-\mathrm{c} k^{\mathrm{T}} \Delta t_{i}^{\mathrm{T}}-d_{\mathrm{MS}}^{\mathrm{SS}_{i}}-\Delta d+\eta_{i} .
\end{aligned}
$$

In formula (10)

$$
\left\{\begin{array}{c}
\Delta t_{i}^{\mathrm{MS}}=t_{\mathrm{DR}_{i}}^{\mathrm{MS}}-t_{\mathrm{DS}_{i}}^{\mathrm{MS}} \\
\Delta t_{i}^{\mathrm{T}}=t_{\mathrm{DR}_{i, 2}}^{\mathrm{T}}-t_{\mathrm{DR}_{i, 1}}^{\mathrm{T}}
\end{array} .\right.
$$

In this system, the local time count value of 1 corresponds to the reference time of $1 /\left(6.4 \times 10^{10}\right)$ second. This value changes due to clock drift, which will be addressed by the following clock offset compensation algorithm. Due to the similar process of each group in one cycle, here we will not repeat. So the localization scheme for $\mathrm{T}$ can be expressed as

$$
\begin{gathered}
d_{\mathrm{MS}}^{\mathrm{T}}-d_{\mathrm{SS}_{1}}^{\mathrm{T}}=\mathrm{c} k^{\mathrm{MS}} \Delta t_{1}^{\mathrm{MS}}-\mathrm{c} k^{\mathrm{T}} \Delta t_{1}^{\mathrm{T}}-d_{\mathrm{MS}_{1}}^{\mathrm{SS}_{1}}-\Delta d+\eta_{1}, \\
d_{\mathrm{MS}}^{\mathrm{T}}-d_{\mathrm{SS}_{2}}^{\mathrm{T}}=\mathrm{c} k^{\mathrm{MS}} \Delta t_{2}^{\mathrm{MS}}-\mathrm{c} k^{\mathrm{T}} \Delta t_{2}^{\mathrm{T}}-d_{\mathrm{MS}}^{\mathrm{SS}_{2}}-\Delta d+\eta_{2}, \\
\vdots \\
d_{\mathrm{MS}}^{\mathrm{T}}-d_{\mathrm{SS}_{L}}^{\mathrm{T}}=\mathrm{c} k^{\mathrm{MS}} \Delta t_{L}^{\mathrm{MS}}-\mathrm{c} k^{\mathrm{T}} \Delta t_{L}^{\mathrm{T}}-d_{\mathrm{MS}}^{\mathrm{SS}_{L}}-\Delta d+\eta_{L} .
\end{gathered}
$$

A further application of equation (12) will be described in detail below.

\section{Compensation for Clock Frequency}

In (12), the clock frequency of blind nodes has a great effect on localization. On the one hand, it is hard to know each blind node's clock frequency if a large number of blind nodes need to be positioned. On the other hand, the localization system is not flexible and practical if blind node's clock frequency must be known for localization. So, here we introduce a method to compensate the effect of blind node's clock frequency drift.

\subsection{Compensation Coefficient of Clock Frequency}

Assume that $x=k^{\mathrm{T}} / k^{\mathrm{MS}}$ and $x$ represents the compensation coefficient. We can estimate the value of $x$ by the observed time stamp in real time to compensate the difference of clock frequency between MS and T. The system signal exchange mechanism is shown in Fig. 5. The time stamp of the MS is transmitted to the blind node to calculate the clock compensation coefficient. The Fig. 5 can be expressed as

$$
\begin{aligned}
& d_{\mathrm{MS}}^{\mathrm{T}}=\mathrm{c}\left(\bar{t}_{\mathrm{TR}_{i, 1}}^{\mathrm{T}}-\bar{t}_{\mathrm{TS}_{i}}^{\mathrm{MS}}\right)=\mathrm{c}\left(\bar{t}_{\mathrm{TR}_{i+1,1}}^{\mathrm{T}}-\bar{t}_{\mathrm{TS}_{i+1}}^{\mathrm{MS}}\right) \\
& \underset{\bar{t}_{\mathrm{TS}}^{\mathrm{MS}}}{\Rightarrow}-\bar{t}_{\mathrm{TS}_{i}}^{\mathrm{MS}}=\bar{t}_{\mathrm{TR}_{i+1,1}}^{\mathrm{T}}-\bar{t}_{\mathrm{TR}_{i, 1}}^{\mathrm{T}} \\
& \Rightarrow \\
& k^{\mathrm{MS}}\left(t_{\mathrm{TS}_{i+1}}^{\mathrm{MS}}-t_{\mathrm{TS}_{i}}^{\mathrm{MS}}\right)=k^{\mathrm{T}}\left(t_{\mathrm{TR}_{i+1,1}}^{\mathrm{T}}-t_{\mathrm{TR}_{i, 1}}^{\mathrm{T}}\right) \\
& \Rightarrow \\
& x=\frac{k^{\mathrm{T}}}{k^{\mathrm{MS}}}=\frac{t_{\mathrm{TS}_{i+1}}^{\mathrm{MS}}-t_{\mathrm{TS}_{i}}^{\mathrm{MS}}}{t_{\mathrm{TR}_{i+1,1}}^{\mathrm{T}}-t_{\mathrm{TR}_{i, 1}}^{\mathrm{T}}}=\frac{t_{\mathrm{DS}_{i+1}}^{\mathrm{MS}}-t_{\mathrm{DS}_{i}}^{\mathrm{MS}}}{t_{\mathrm{DR}_{i+1,1}}^{\mathrm{T}}-t_{\mathrm{DR}_{i, 1}}^{\mathrm{T}}}+\varphi_{i} .
\end{aligned}
$$

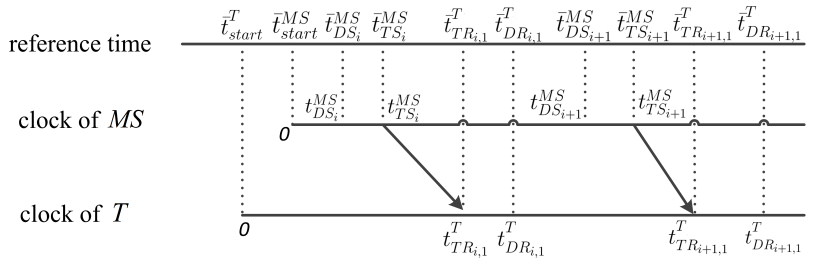

Fig. 5. Signal exchange for compensation coefficient. 
There is a small error between the time difference $t_{\mathrm{TS}_{i+1}}^{\mathrm{MS}}-t_{\mathrm{TS}_{i}}^{\mathrm{MS}}$ and $t_{\mathrm{DS}_{i+1}}^{\mathrm{MS}}-t_{\mathrm{DS}_{i}}^{\mathrm{MS}}$ due to the influence of the circuit transmission noise. Similarly, there is a small error between $t_{\mathrm{TR}_{i+1,1}}^{\mathrm{T}}-t_{\mathrm{TR}_{i, 1}}^{\mathrm{T}}$ and $t_{\mathrm{DR}_{i+1,1}}^{\mathrm{T}}-t_{\mathrm{DR}_{i, 1}}^{\mathrm{T}}, \varphi_{i}$ is the ratio between these two small error terms.

Suppose that $w$ represents the measured value of $x$ in one cycle. $w$ can be expressed as

$$
w=\frac{1}{L-1} \sum_{i=1}^{L-1} \frac{t_{\mathrm{DS}_{i+1}}^{\mathrm{MS}}-t_{\mathrm{DS}_{i}}^{\mathrm{MS}}}{t_{\mathrm{DR}_{i+1,1}}^{\mathrm{T}}-t_{\mathrm{DR}_{i, 1}}^{\mathrm{T}}} .
$$

In (14), $\mathrm{L}$ is the number of SS. The relationship between $x$ and $w$ can be expressed as

$$
w=x+\varphi
$$

In (15), $\varphi$ can be treated as Gauss white noise with zero means. $\varphi$ is the cumulative average of $\varphi_{i}$. Here Kalman filter algorithm is used to estimate the optimal value of $x$.

\subsection{Application of Kalman Filter Algorithm}

The value of $x$ is usually stable and affected by the Gauss white noise in a very short time interval. Assume that $x_{n}$ and $x_{n+1}$ represent the compensation coefficient in $n^{\text {th }}$ and $(n+1)^{\text {th }}$ cycle respectively. The state equation can be expressed as

$$
x_{n+1}=x_{n}+\phi \text {. }
$$

$\operatorname{In}(16), \phi$ is additive white Gaussian noise with zero mean. Assume that $w_{n}$ represents the measured value of $x_{n}$ in $n^{\text {th }}$ cycle. The measurement equation can be expressed as

$$
w_{n}=x_{n}+\varphi
$$

According to (16) and (17), the Kalman filter algorithm can be expressed as

$$
\begin{aligned}
& \hat{x}_{n+1}=\hat{x}_{n}+G_{n}\left(w_{n+1}-\hat{x}_{n}\right), \\
& \hat{x}_{1}=E\left(x_{1}\right) .
\end{aligned}
$$

In (18), $G_{n}$ represents the Kalman gain coefficient. $E\left(x_{1}\right)$ represents the expected value of $x_{1}$. The filter system is a linear time-invariant system. The limiting Kalman filter algorithm [23] can be applied to this system. It can be proved that $\left\{G_{n}\right\}$ is convergent on the condition that the linear system changes very smoothly. Suppose that $G=\lim _{n \rightarrow \infty} G_{n}$. So the limiting Kalman filter algorithm can be expressed as

$$
\begin{aligned}
& \hat{x}_{n+1}=\hat{x}_{n}+G\left(w_{n+1}-\hat{x}_{n}\right), \\
& \hat{x}_{1}=E\left(x_{1}\right) .
\end{aligned}
$$

\subsection{The Clock Frequency of MS}

In a practical design, there exists the clock frequency drift in MS because the variety of surrounding environment such as pressure and temperature. Usually, the random variables can be modelled as white Gaussian noise when the clock system of MS is in fully stable operation. Assume that $k_{\text {mean }}^{\mathrm{MS}}$ and $\eta^{\mathrm{MS}}$ represent the expected value of MS' clock frequency and random variable respectively. The $k^{\mathrm{MS}}$ can be expressed as

$$
k^{\mathrm{MS}}=k_{\text {mean }}^{\mathrm{MS}}+\eta^{\mathrm{MS}}
$$

\subsection{The TDOA Localization}

According to (12), (19), (20), the TDOA localization model for $\mathrm{T}$ can be expressed as

$$
\begin{aligned}
d_{\mathrm{MS}}^{\mathrm{T}}-d_{\mathrm{SS}_{1}}^{\mathrm{T}}= & \mathrm{c} k_{\mathrm{mean}}^{\mathrm{MS}}\left(\Delta t_{1}^{\mathrm{MS}}-\hat{x} \Delta t_{1}^{\mathrm{T}}\right)-d_{\mathrm{MS}_{1}}^{\mathrm{SS}_{1}}-\Delta d+\gamma_{1}, \\
d_{\mathrm{MS}}^{\mathrm{T}}-d_{\mathrm{SS}_{2}}^{\mathrm{T}}= & \mathrm{c} k_{\text {mean }}^{\mathrm{MS}}\left(\Delta t_{2}^{\mathrm{MS}}-\hat{x} \Delta t_{2}^{\mathrm{T}}\right)-d_{\mathrm{MS}}^{\mathrm{SS}_{2}}-\Delta d+\gamma_{2}, \\
& \vdots \\
d_{\mathrm{MS}}^{\mathrm{T}}-d_{\mathrm{SS}_{L}}^{\mathrm{T}}= & \mathrm{c} k_{\text {mean }}^{\mathrm{MS}}\left(\Delta t_{L}^{\mathrm{MS}}-\hat{x} \Delta t_{L}^{\mathrm{T}}\right)-d_{\mathrm{MS}}^{\mathrm{SS}_{L}}-\Delta d+\gamma_{L}
\end{aligned}
$$

In (21), $\gamma_{1}, \gamma_{2}, \gamma_{L}$ represent the white Gaussian noise with zero mean. Suppose

$$
\begin{gathered}
r=\mathrm{c} k_{\mathrm{mean}}^{\mathrm{MS}}, \\
d_{i}=d_{\mathrm{MS}}^{\mathrm{T}}-d_{\mathrm{SS}_{i}}^{\mathrm{T}}+d_{\mathrm{MS}}^{\mathrm{SS}_{i}}(i=1,2 \ldots L), \\
t_{i}=\Delta t_{i}^{\mathrm{MS}}-\hat{x} \Delta t_{i}^{\mathrm{T}}(i=1,2 \ldots L),
\end{gathered}
$$

$r$ and $\Delta d$ are determined by the clock frequency and time delay of MS, so the value of the two parameters don't change with the localization of different blind nodes. $t_{i}$ represent the time data of $\mathrm{T}$, which can be calculated by the available time stamp in one cycle. Placing the MS and SSs at the determined coordinate position, recording the time stamp information of the MS transmission signal and the time stamp information of the reception signal, calculating $\Delta t_{i}^{\mathrm{MS}}$ by (11), simultaneously recording the time stamp information of the blind node reception signal, calculating $\Delta t_{i}^{\mathrm{T}}$. Then $t_{i}$ can be calculated by (24). In (23), $d_{\mathrm{MS}}^{\mathrm{SS}_{i}}$ represents the constant distance from MS to the slave station $i\left(\mathrm{SS}_{i}\right), d_{\mathrm{MS}}^{\mathrm{T}}-d_{\mathrm{SS}_{i}}^{\mathrm{T}}$ represents the distance difference from $\mathrm{T}$ to $\mathrm{MS}$ and $S S_{i}$. Since the location of MS and SSs are known, $d_{i}$ can be measured. $r$ and $\Delta d$ can be obtained by collecting multiple sets of data and performing linear fitting by using the least square method. The location of blind nodes can be estimated by calculating a series of distance difference according to (21). In this paper, Taylor iterative algorithm is adopted to calculate the location of blind nodes because it produces high accuracy with proper computational complexity.

Taking one MS and three SSs as examples, the location process of a blind node is briefly introduced. Since the positions of all the base stations are known, $d_{\mathrm{MS}}^{\mathrm{SS}_{i}}$ is a known 
value, and the value of $d_{\mathrm{SS}_{i}}^{\mathrm{T}}-d_{\mathrm{MS}}^{\mathrm{T}}$ can be obtained from (21). To simplify the expression, use subscript 1 represents MS, 2/3/4 are SSs, and 5 represents blind node. For example, $d_{15}$ means the distance between MS and blind node.

$$
\begin{aligned}
& R_{\mathrm{a}}=d_{15}-d_{25}, \\
& R_{\mathrm{b}}=d_{15}-d_{35}, \\
& R_{\mathrm{c}}=d_{15}-d_{45} .
\end{aligned}
$$

Assume that the base station coordinates are $P_{i}\left(x_{i}, y_{i}, z_{i}\right), i=1,2,3,4$ and the initial value of blind node position is $\hat{P}_{0}\left(\hat{x}_{0}, \hat{y}_{0}, \hat{z}_{0}\right)$, then, the $n^{\text {th }}$ times of iteration position is $\hat{P}_{n}\left(\hat{x}_{n}, \hat{y}_{n}, \hat{z}_{n}\right)$.

$$
\begin{gathered}
\hat{x}_{n+1}=\hat{x}_{n}+\Delta \hat{x}_{n}, \\
\hat{y}_{n+1}=\hat{y}_{n}+\Delta \hat{y}_{n}, \\
\hat{z}_{n+1}=\hat{z}_{n}+\Delta \hat{z}_{n}, \\
\hat{P}_{n}=\left[\begin{array}{lll}
\hat{x}_{n} & \hat{y}_{n} & \hat{z}_{n}
\end{array}\right]^{\mathrm{T}}, \\
\hat{P}_{n+1}=\left[\begin{array}{lll}
\hat{x}_{n+1} & \hat{y}_{n+1} & \hat{z}_{n+1}
\end{array}\right]^{\mathrm{T}} .
\end{gathered}
$$

Accord to Taylor iteration algorithm [24],

$$
\hat{P}_{n+1}=\hat{P}_{n}+\left(A_{n}^{\mathrm{T}} Q_{t}^{-1} A_{n}\right)^{-1} A_{n}^{\mathrm{T}} Q_{t}^{-1} r_{n} .
$$

In (29),

$$
\begin{gathered}
r_{n}=\left[\begin{array}{l}
R_{\mathrm{a}}-d_{15}+d_{25} \\
R_{\mathrm{b}}-d_{15}+d_{35} \\
R_{\mathrm{c}}-d_{15}+d_{45}
\end{array}\right], \\
A_{n}=\left[\begin{array}{lll}
\frac{\hat{x}_{n}-x_{1}}{d_{15}}-\frac{\hat{x}_{n}-x_{2}}{d_{25}} & \frac{\hat{y}_{n}-y_{1}}{d_{15}}-\frac{\hat{y}_{n}-y_{2}}{d_{25}} & \frac{\hat{z}_{n}-z_{1}}{d_{15}}-\frac{\hat{z}_{n}-z_{2}}{d_{25}} \\
\frac{\hat{x}_{n}-x_{1}}{d_{15}}-\frac{\hat{x}_{n}-x_{3}}{d_{35}} & \frac{\hat{y}_{n}-y_{1}}{d_{15}}-\frac{\hat{y}_{n}-y_{3}}{d_{35}} & \frac{z_{n}-z_{1}}{d_{15}}-\frac{\hat{z}_{n}-z_{3}}{d_{35}} \\
\frac{\hat{x}_{n}-x_{1}}{d_{15}}-\frac{\hat{x}_{n}-x_{4}}{d_{45}} & \frac{\hat{y}_{n}-y_{1}}{d_{15}}-\frac{\hat{y}_{n}-y_{4}}{d_{45}} & \frac{\hat{z}_{n}-z_{1}}{d_{15}}-\frac{\hat{z}_{n}-z_{4}}{d_{45}}
\end{array}\right],
\end{gathered}
$$

$Q_{t}$ is the covariance matrix of the reference time. $R_{\mathrm{a}}$, $R_{\mathrm{b}}, R_{\mathrm{c}}$ are measured by system and $d_{15}, d_{25}, d_{35}, d_{45}$ are calculated from the estimated coordinates. The iteration is performed until the position increment satisfies

$$
\Delta \hat{x}_{n}^{2}+\Delta \hat{y}_{n}^{2}+\Delta \hat{z}_{n}^{2}<\varepsilon^{2}
$$

Then, the real position of the blind node can be obtained. In (32), $\varepsilon$ is the default threshold value.

\section{Experiment in LOS Environment}

In this paper, the TDOA ranging scheme is established with a linear model, and the experiment has been carried out in LOS environment to verify the feasibility of the proposed scheme. What's more, the value of $r$ and $\Delta d$ has been estimated with least square estimation algorithm.

\subsection{Experimental Condition}

In the experiment, the localization system contains a master station, three slave stations, and a blind node. The hardware is UWB indoor localization module based on DWM1000 chip. The chip has the function of transmitting and receiving signals, and the high-frequency clock is integrated into the chip, which can provide the receiving time stamp and the transmitting time stamp. The circuit board is shown in Fig. 6. The specific experimental procedure is as follows.

1) Select the appropriate experimental site. Fix MS and 3 SSs in the suitable position, so that their spatial distribution can obtain good GDOP(Geometric Dilution Precision) value which represents the distance vector amplification factor between the receiver and the base station caused by the ranging error. In order to realize 3-dimensional positioning, at least 4 base stations are needed. $1 \mathrm{MS}$ and 3 SSs is the simplest case, which is easy to realize and convenient to discuss.

The calculation method of GDOP is as follows, assuming that four base stations are used for positioning, the coordinates of these four base stations are recorded as $\left(X_{s 1}, Y_{s 1}, Z_{s 1}\right),\left(X_{s 2}, Y_{s 2}, Z_{s 2}\right),\left(X_{s 3}, Y_{s 3}, Z_{s 3}\right),\left(X_{s 4}, Y_{s 4}, Z_{s 4}\right)$, and the coordinates of the estimated point $A$ be $\left(X_{A}, Y_{A}, Z_{A}\right)$. Its GDOP value is

$$
\operatorname{GDOP}_{A}=\left\{\operatorname{trace}\left(\left\{G_{A}^{\mathrm{T}} G_{A}\right\}^{-1}\right)\right\}^{\frac{1}{2}}
$$

where trace $(\cdot)$ represents the trace of the matrix, $\mathrm{T}$ is the transpose of the matrix. And $G_{A}$ is

$$
G_{A}=\left[\begin{array}{ccc}
\cos \alpha_{A 1} & \cos \beta_{A 1} & \cos \gamma_{A 1} \\
\cos \alpha_{A 2} & \cos \beta_{A 2} & \cos \gamma_{A 2} \\
\cos \alpha_{A 3} & \cos \beta_{A 3} & \cos \gamma_{A 3} \\
\cos \alpha_{A 4} & \cos \beta_{A 4} & \cos \gamma_{A 4}
\end{array}\right]
$$

where

$$
\left\{\begin{array}{l}
\cos \alpha_{A i}=\frac{X_{s i}-X_{A}}{D_{A i}} \\
\cos \beta_{A i}=\frac{Y_{s i} Y_{A}}{D_{A i}} \\
\cos \gamma_{A i}=\frac{Z_{s i}-Z_{A}}{D_{A i}}
\end{array}\right.
$$

and $D_{A i}=\sqrt{\left(X_{s i}-X_{A}\right)^{2}+\left(Y_{s i}-Y_{A}\right)^{2}+\left(Z_{S i}-Z_{A}\right)^{2}}$ is the distance from base station $i$ to point $A$.

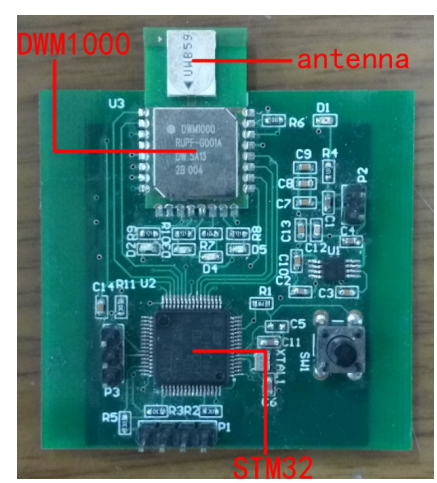

Fig. 6. UWB indoor localization circuit board. 
2) Let all the nodes work for a period of time, so that their clock system are in fully stable operation.

3) Fix the blind node in a test point. Measure and record the distance from the blind node to MS and 3 SSs.

4) Make the system work for a period of time, and record the time stamp of MS and the blind node.

5) Select 15 test points, and repeat step (3), (4) for each test point.

The true distances between 15 test points and the base stations are shown in Tab. 1.

\subsection{The Results of Ranging}

A total of 15 groups of experiments were carried out to verify the feasibility of the proposed scheme. Generally, the smaller value of $G$, the better filtering performance, but the higher delay. In this paper, the value of $G$ is chosen as 0.01 . As is shown in Fig. 7, the clock offset compensation coefficient $w$ fluctuates slightly before filtering at each sampling point due to noise interference, by using Kalman filtering algorithm, it can be seen that the noise can be effectively filtered out and the optimal value of the compensation coefficient can be estimated in real time. In order to show the influence of frequency offset compensation coefficient on ranging more intuitively, the ranging results obtained with and without frequency offset compensation are shown in Tab. 2. Three distances can be obtained for each point, and definition $R_{1}=d_{15}+d_{12}-d_{25}, R_{2}=d_{15}+d_{13}-d_{35}, R_{3}=d_{15}+d_{14}-d_{45}$. Take two test points for analysis. From table 2, we can see that the ranging error is effectively reduced with frequency offset compensation. The ranging error is shown in Fig. 8, and the error is $229 \mathrm{~mm}$ (RMS).

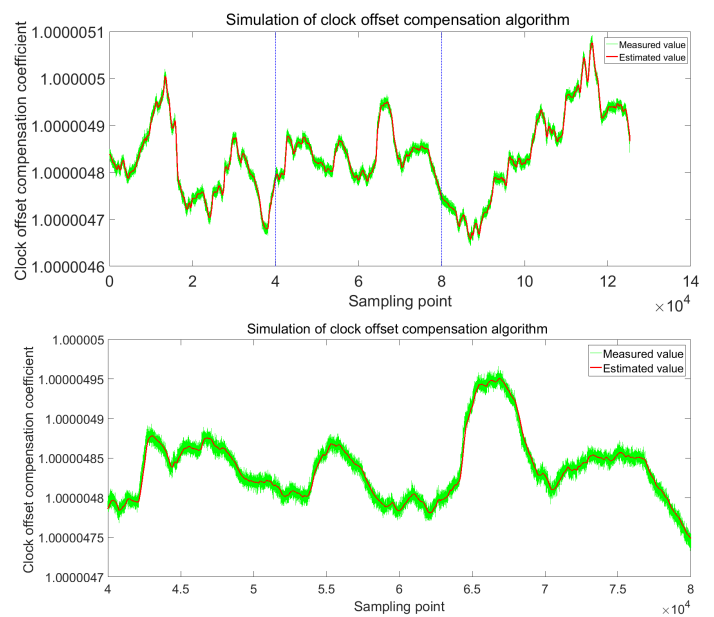

Fig. 7. The compensation coefficient. a) Original, b) Partial amplification.

\begin{tabular}{|c|c|c|c|c|c|c|c|}
\hline Test point & $d_{12}[\mathrm{~mm}]$ & $d_{13}[\mathrm{~mm}]$ & $d_{14}[\mathrm{~mm}]$ & $d_{15}[\mathrm{~mm}]$ & $d_{25}[\mathrm{~mm}]$ & $d_{35}[\mathrm{~mm}]$ & $d_{45}[\mathrm{~mm}]$ \\
\hline 1 & 6676 & 10294 & 7850 & 1598 & 5694 & 8746 & 6844 \\
\hline 2 & 6676 & 10294 & 7850 & 2498 & 4602 & 8084 & 7104 \\
\hline 3 & 6676 & 10294 & 7850 & 3532 & 3520 & 7504 & 7502 \\
\hline 4 & 6676 & 10294 & 7850 & 4600 & 2490 & 7116 & 8110 \\
\hline 5 & 6676 & 10294 & 7850 & 5666 & 1624 & 6834 & 8739 \\
\hline 6 & 6676 & 10294 & 7850 & 6470 & 3544 & 4661 & 7158 \\
\hline 7 & 6676 & 10294 & 7850 & 5636 & 4062 & 4990 & 6374 \\
\hline 8 & 6676 & 10294 & 7850 & 4758 & 4789 & 5580 & 5598 \\
\hline 9 & 6676 & 10294 & 7850 & 4028 & 5609 & 6335 & 5049 \\
\hline 10 & 6676 & 10294 & 7850 & 3586 & 6560 & 7169 & 4662 \\
\hline 11 & 6676 & 10294 & 7850 & 5712 & 7929 & 6020 & 2548 \\
\hline 12 & 6676 & 10294 & 7850 & 6006 & 7218 & 5063 & 3208 \\
\hline 13 & 6676 & 10294 & 7850 & 6506 & 6568 & 4048 & 4054 \\
\hline 14 & 6676 & 10294 & 7850 & 7162 & 6098 & 3175 & 4996 \\
\hline 15 & 6676 & 10294 & 7850 & 7892 & 5768 & 2546 & 6026 \\
\hline
\end{tabular}

Tab. 1. The distances between 15 test points and each base station.

\begin{tabular}{|l|ccc|ccc|}
\hline & \multicolumn{3}{|c|}{ Test point1 } & \multicolumn{3}{c|}{ Test point2 } \\
\hline Distance & R1 & R2 & R3 & R1 & R2 & R3 \\
\hline Real distance & 2580 & 3146 & 2604 & 4572 & 4708 & 3244 \\
\hline $\begin{array}{l}\text { Ranging average with } \\
\text { compensation coefficient }\end{array}$ & 2440 & 2948 & 2401 & 4301 & 5146 & 3080 \\
\hline $\begin{array}{l}\text { Ranging error with } \\
\text { compensation coefficient }\end{array}$ & -140 & -198 & -203 & -271 & 438 & -164 \\
\hline $\begin{array}{l}\text { Ranging average without } \\
\text { compensation coefficient }\end{array}$ & 3910 & 4389 & 3830 & 5767 & 6524 & 4549 \\
\hline $\begin{array}{l}\text { Ranging error without } \\
\text { compensation coefficient }\end{array}$ & 1330 & 1243 & 1226 & 1195 & 1816 & 1305 \\
\hline
\end{tabular}

Tab. 2. Influence of frequency offset compensation coefficient on ranging (unit:mm). 


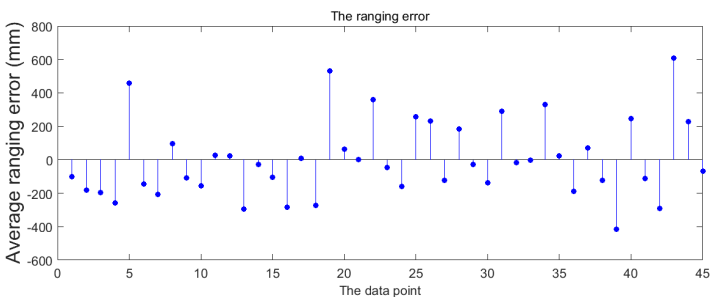

Fig. 8. The difference between calculated distance and measured distance.

\subsection{Indoor Location Experiment}

In order to verify the performance of indoor localization, the indoor static and dynamic localization experiments have been carried out. Space rectangular coordinate system is established, the MS and SSs are fixed in the appropriate positions in the laboratory. The specific layout is shown in Fig. 9.

In the indoor static localization experiment, 15 positions are chosen as the experimental site and fix the blind node with $1500 \mathrm{~mm}$ height. The schematic diagram of the test points is shown in Fig. 10. The localization results of the static localization experiment are shown in Fig. 11.

As is shown in Fig. 11, the position coordinate values of the $\mathrm{X}$-axis and $\mathrm{Y}$-axis are highly stable when the blind node is in a stationary state. The CDF function of the positioning error of each axis and the total error is shown in Fig. 12, and the localization error in X-axis and in Y-axis is $166 \mathrm{~mm}$ (RMS) and $119 \mathrm{~mm}$ (RMS) respectively. The 2D positioning accuracy is $\sqrt{166^{2}+119^{2}}=204 \mathrm{~mm}$ (RMS). The localization error in $\mathrm{Z}$ axis is $483 \mathrm{~mm}$ (RMS). The positioning solution is inversely proportional to GDOP. The smaller GDOP value, the higher positioning accuracy obtained. Table 3 summarizes the experimental results of UWB positioning system published in recent years.
In the indoor dynamic localization experiment, four key points are selected, the motion track starts from the first point, sequentially passes through the other key points and finally returns to the first point, the location results at the key points are shown in Tab. 4. The trajectory of the blind node in the $\mathrm{XY}$ plane is shown in Fig. 13. The coordinates of the blind node are shown in Fig. 14.

The results of the indoor static and dynamic localization experiment demonstrates that the localization scheme designed in this paper can achieve 3-D localization with high accuracy. Due to the limitation of the experimental environment, the height difference between the base stations is not large, VDOP(Vertical dilution precision) is large, so the positioning error of $\mathrm{Z}$-axis is higher than that of $\mathrm{X}$-axis and Y-axis. Improving the spatial distribution of base stations can improve the positioning accuracy [30].

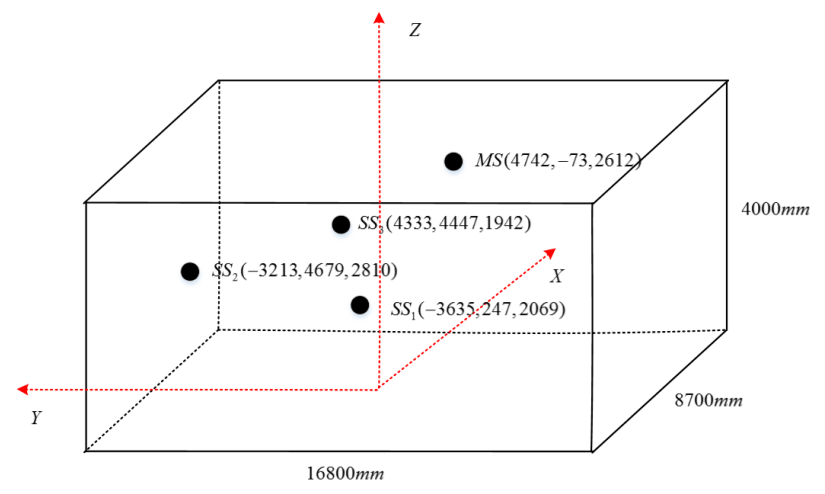

Fig. 9. The installation layout.

\begin{tabular}{|c|c|l|c|l|}
\hline Ref & Technique & Architecture & Accuracy(2D) & Feature \\
\hline$[18]$ & sequential-TDOA & Tiny TriSOS & $1 \mathrm{~m}$ & $\begin{array}{l}\text { Low precision, low cost, no limit on the number of } \\
\text { blind nodes.No need global clock synchronization, but } \\
\text { no clock drift compensation. }\end{array}$ \\
\hline$[25]$ & TDOA & Ubisense & $13-23 \mathrm{~cm}$ & $\begin{array}{l}\text { High precision, medium cost, good robustness. Blind } \\
\text { nodes need actively transmit signals. Use time syn- } \\
\text { chronization line. }\end{array}$ \\
\hline$[26]$ & TOA & $\begin{array}{l}\text { Pulse generator } \\
\text { Oscilloscope }\end{array}$ & $7.4 \mathrm{~cm}$ & $\begin{array}{l}\text { High precision, high cost, wired connection restriction } \\
\text { layout. Using pulse synchronization generator. }\end{array}$ \\
\hline$[27]$ & Two-way TOA & WLAN RFIC & $50 \mathrm{~cm}$ & $\begin{array}{l}\text { Low precision, low cost, blind nodes need actively } \\
\text { transmit signals. No need for global clock synchro- } \\
\text { nization. }\end{array}$ \\
\hline$[28]$ & Two-way TOA & $\begin{array}{l}\text { Pulse generator } \\
\text { Energy detector }\end{array}$ & $29 \mathrm{~cm}$ & $\begin{array}{l}\text { Medium precision, low cost, blind nodes need actively } \\
\text { transmit signals. No need for global clock synchro- } \\
\text { nization. }\end{array}$ \\
\hline$[29]$ & asynchronous-TDOA & $\begin{array}{l}\text { Pulse generator } \\
\text { Energy detector }\end{array}$ & $15.2 \mathrm{~cm}$ & $\begin{array}{l}\text { High precision, low cost, blind nodes need actively } \\
\text { transmit signals.No need for global clock synchroniza- } \\
\text { tion. }\end{array}$ \\
\hline This work & sync-free TDOA & DW1000 & $20.4 \mathrm{~cm}$ & $\begin{array}{l}\text { High precision, low cost, blind nodes passively receive } \\
\text { the signal. No need for global clock synchronization. } \\
\text { Automatic compensation of clock drift. }\end{array}$ \\
\hline
\end{tabular}

Tab. 3. Comparison with the exiting systems. 


\begin{tabular}{|c|c|c|c|c|c|c|c|}
\hline \multirow{2}{*}{ Number } & \multicolumn{3}{|c|}{ Key point coordinates } & \multicolumn{3}{|c|}{ Location results } & \multirow{2}{*}{$\begin{array}{l}\text { Positioning } \\
\text { error }\end{array}$} \\
\hline & $\mathbf{X}$ & $\mathbf{Y}$ & $\mathbf{Z}$ & $\mathbf{X}$ & $\mathbf{Y}$ & $\mathbf{Z}$ & \\
\hline 1 & 0 & 0 & 0 & 233 & -186 & -258 & 394 \\
\hline 2 & 0 & 4806 & 1500 & 48 & 4736 & 1278 & 238 \\
\hline 3 & 1140 & 4806 & 1500 & 1328 & 4767 & 1706 & 282 \\
\hline 4 & 1140 & 0 & 1500 & 1193 & -108 & 1204 & 320 \\
\hline
\end{tabular}

Tab. 4. Indoor dynamic positioning experiment data (unit:mm).

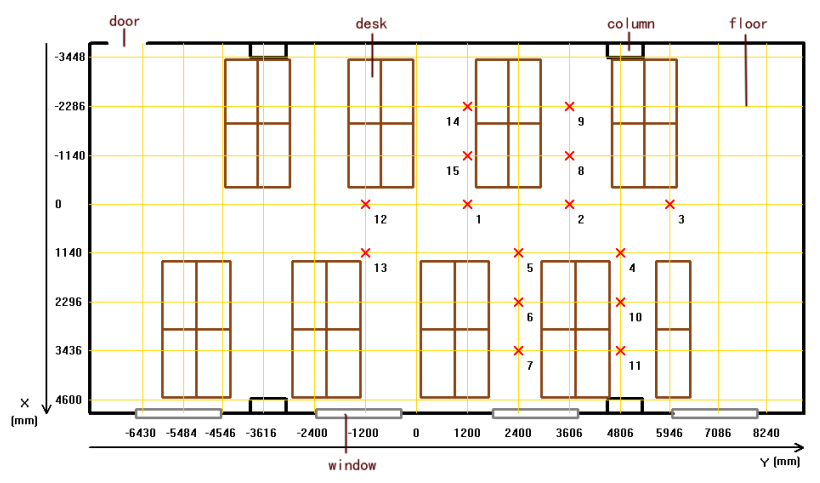

Fig. 10. The position of the test points.
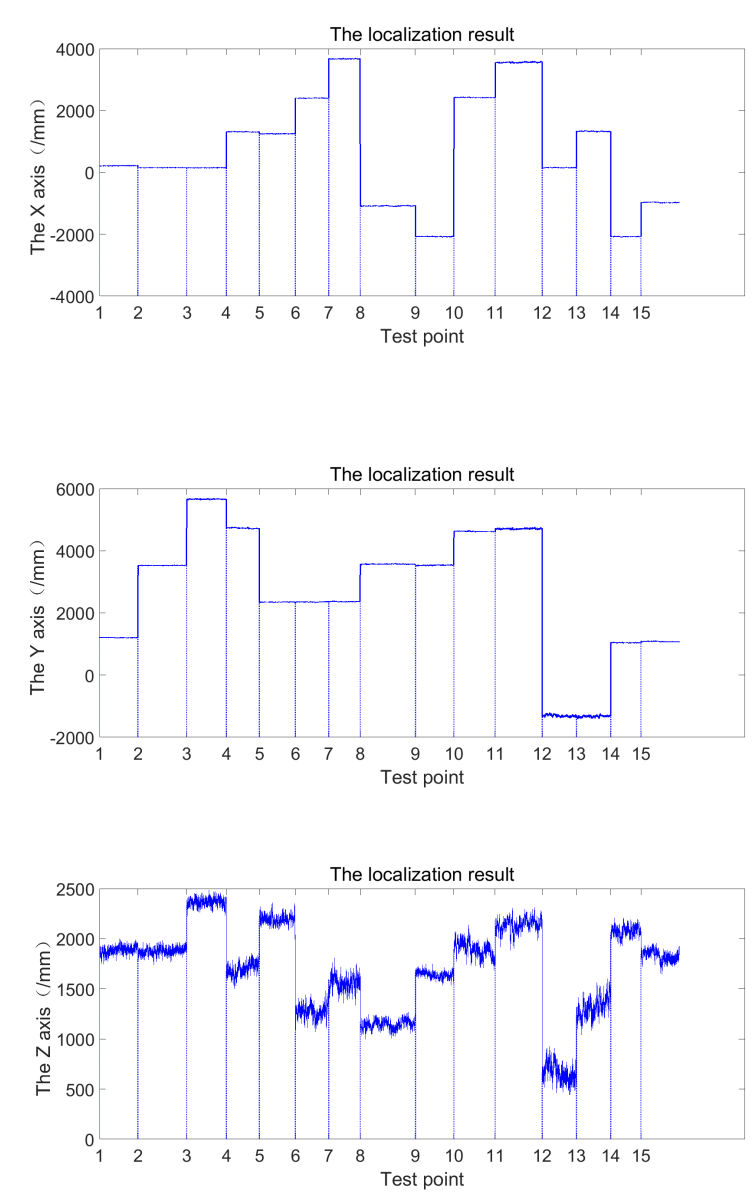

Fig. 11. The location coordinates of test points. a) X-axis, b) Y-axis, c) Z-axis.

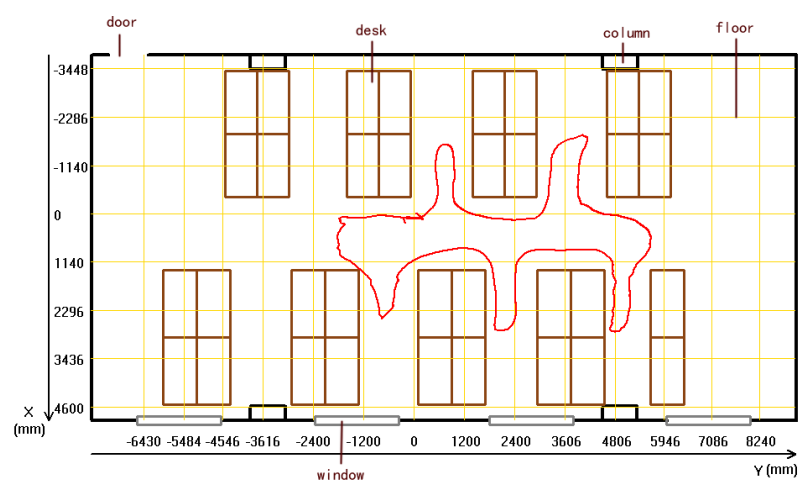

Fig. 13. The experimental trajectory of blind node in XY plane.
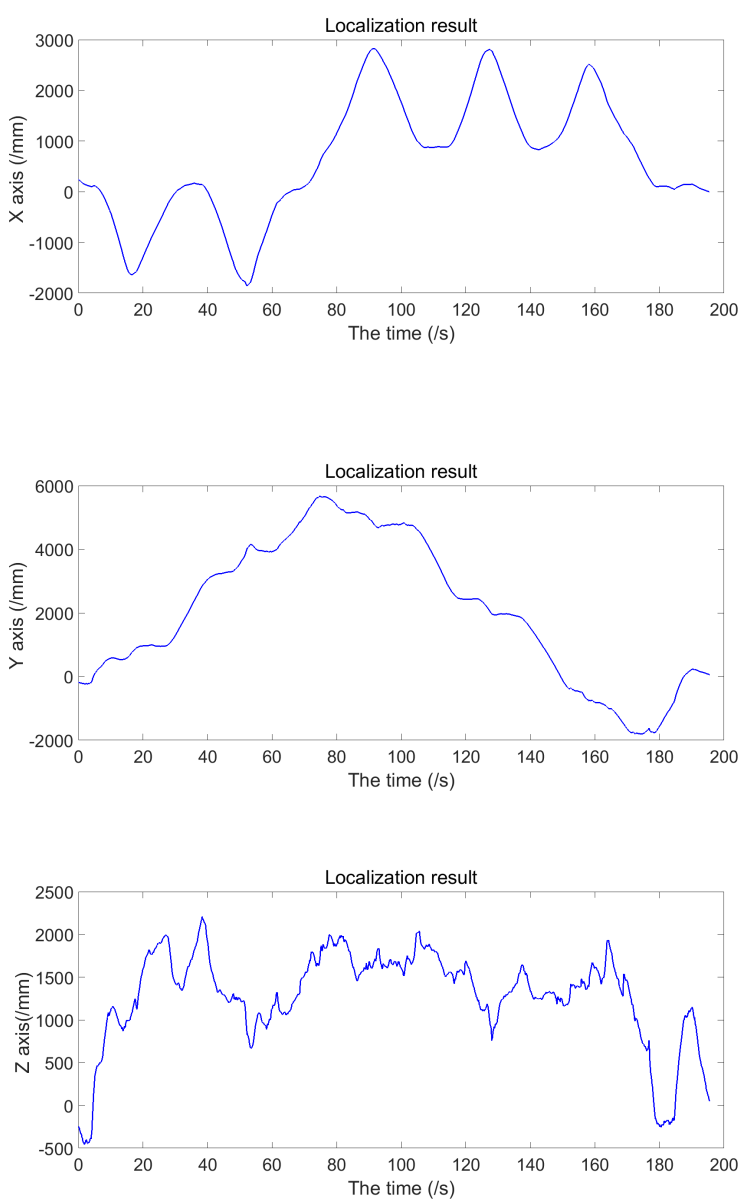

Fig. 14. The dynamic location coordinates. a) X-axis, b) Y-axis, c) Z-axis. 

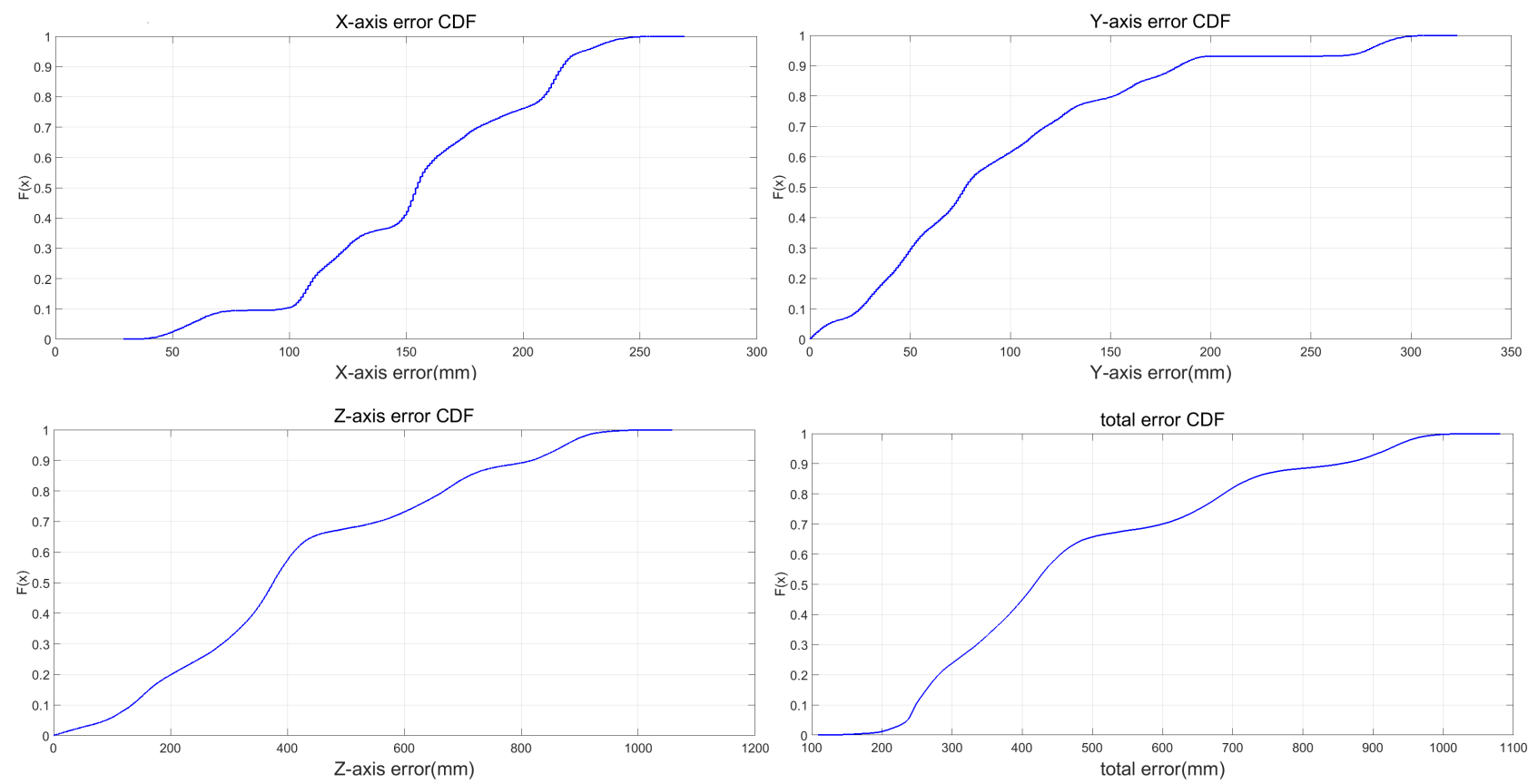

Fig. 12. The CDF function of the location error of each axis and the total error. a) X-axis, b) Y-axis, c) Z-axis, d) total.

\section{Conclusion}

A new synchronization-free TDOA localization system based on UWB is proposed in this paper. First of all, the clock is modelled with starting time and clock frequency to establish a unified clock system for time synchronization. Then, the system signal exchange mechanism is proposed to establish the linear TDOA localization model. In order to compensate the difference of clock frequency, the Kalman Filter algorithm is applied to estimate the compensation coefficient of clock frequency. Finally, the coordinates of the blind nodes is obtained by the Taylor iterative algorithm. The indoor localization experiment shows that the indoor localization system designed in this paper can achieve 3-D localization with high localization accuracy.

\section{Acknowledgments}

This work is supported by the National Natural Science Foundation (No. 61571148, No. 61871143), Fundamental Research for the Central University (No. HEUCFG201823, No. HEUCFP201836), Research and Development Project of Application Technology in Harbin (No. 2017R-AQXJ095).

\section{References}

[1] SHEN, J., MOLISCH, A., SALMI, J. Accurate passive location estimation using TOA measurements. IEEE Transactions on Wireless Communications, 2012, vol. 11, no. 6, p. 2182-2192. ISSN: 1536-1276. DOI: 10.1109/TWC.2012.040412.110697
[2] LI, D., ZHANG, B., LI, C. A feature-scaling-based k-nearest neighbour algorithm for indoor positioning systems. IEEE Internet of Things Journal, 2016, vol. 3, no. 4, p. 590-597. ISSN: 2327-4662. DOI: 10.1109/JIOT.2015.2495229

[3] MARDENI, R., OTHMAN, S. Efficient mobile asset tracking and localization in ZigBee wireless network. Journal of Advances in Computer Networks, 2015, vol. 3, no. 1, p. 1-6. ISSN: 1793-8244. DOI: $10.7763 /$ JACN.2015.V3.132

[4] XU, H., DING, Y., LI, P., et al. An RFID indoor positioning algorithm based on bayesian probability and K-nearest neighbor. Sensors, 2017, vol. 17 , no. 8,17 p. ISSN: 1424-8220. DOI: $10.3390 / \mathrm{s} 17081806$

[5] YANG, C., SHAO, H. WiFi-based indoor positioning. IEEE Communications Magazine, 2015, vol. 53, no. 3, p. 150-157. ISSN: 0163-6804. DOI: 10.1109/MCOM.2015.7060497

[6] HUH, J.H., SEO, K. An indoor location-based control system using Bluetooth beacons for IoT systems. Sensors, 2017, vol. 17, no. 12, 22 p. ISSN: 1424-8220. DOI: 10.3390/s17122917

[7] WANG, Y.K., FAN, H., CHEN, R.Z., et al. Positioning locality using cognitive directions based on indoor landmark reference system. Sensors, 2018, vol. 18, no. 4, 20 p. ISSN: 1424-8220. DOI: $10.3390 / \mathrm{s} 18041049$

[8] NARDIS, L., FIORINA, J., PANAITOPOL, D., BENEDETT, M. Combining UWB with time reversal for improved communication and positioning. Telecommunication Systems, 2013, vol. 52, no. 2, p. $1145-1158$. ISSN: $1018-4864$. DOI: $10.1007 / \mathrm{s} 11235-011-9630-1$

[9] MEISSNER, P., LEITINGER, E., WITRISAL, K. UWB for robus indoor tracking: Weighting of multipath components for efficient estimation. IEEE Wireless Communications Letters, 2014, vol. 3, no. 5, p. 501-504. ISSN: 2162-2337. DOI: 10.1109/LWC.2014.2341636

[10] SILVA, B., HANCKE, G. IR-UWB-based non-line-of-sight identification in harsh environments: principles and challenges. IEEE Transactions on Industrial Informatics, 2016, vol. 12, no. 3, p. 1188-1195. ISSN: 1551-3203. DOI: 10.1109/TII.2016.2554522 
[11] GARCIA, E., POUDEREUX, P., et al. A robust UWB indoor positioning system for highly complex environments. In Proceedings of the IEEE International Conference on Industrial Technology (ICIT). Seville (Spain), 2015, p. 3386-3391. ISBN: 978-1-4799-7800-7. DOI: 10.1109/ICIT.2015.7125601

[12] SHEN, Y., WIN, M. Fundamental limits of wideband localization:Part I: A general framework. IEEE Transactions on Information Theory, 2010, vol. 56, no. 10, p. 4956-4980. ISSN: 0018-9448. DOI: $10.1109 /$ TIT.2010.2060110

[13] BOGDANI, E., VOUYIOUKAS, D., NOMIKOS, N. Localization error modelling of hybrid fingerprint-based techniques for indoor ultrawideband systems. Telecommunication Systems, 2016, vol. 63, no. 2, p. 223-241. ISSN: 1018-4864. DOI: 10.1007/s11235-015-0116-4

[14] MEGHANI, S., ASIF, M. Localization of WSN node based on RTT ToA using ultra wide band 802.15.4a channel. In Proceedings of the IEEE International Conference on Networking, Sensing and Control. Miami (USA), 2014, p. 380-385. DOI: 10.1109/ICNSC.2014.6819656

[15] WANG, T., CHENT, X., GE, N., PEI, Y. Error analysis and experimental study on indoor UWB TDoA localization with reference tag. In Proceedings of the Asia-Pacific Conference on Communications (APCC). Denpasar (Indonesia), 2013, p. 505-508. DOI: 10.1109/APCC.2013.6766000

[16] BIN, X., RAN, Y. et al. Whistle: Synchronization-free TDOA for localization. In Proceedings of the International Conference on Distributed Computing Systems. Minneapolis (USA), 2011, p. 760-769. ISBN: 978-0-7695-4364-2. DOI: 10.1109/ICDCS.2011.30

[17] LEE, J.X., LIN, Z.W., et al. A scheme to compensate time drift in time difference of arrival localization among non-synchronized sensor nodes. In Proceedings of the IEEE Vehicular Technology Conference. Barcelona (Spain), 2009, p. 1-4. ISSN: 15502252. DOI: 10.1109/VETECS.2009.5073339

[18] MATHIAS, P., HORST, H. S-TDoA-Sequential time difference of arrival a scalable and synchronization free approach for positioning. In Proceedings of the IEEE Wireless Communications and Networking Conference. Doha (Qatar), 2016, p. 1-6. ISSN: 15253511. DOI: 10.1109/WCNC.2016.7565024

[19] NAM, Y.-S., et al. Wirelessly synchronized one-way ranging algorithm with active mobile nodes. ETRI Journal, 2009, vol. 31, no. 4, p. 466-468. ISSN: 1225-6463. DOI: 10.4218/etrij.09.0208.0305

[20] ANGELIS, G., MOSCHITTA, A., CARBONE, P. Positioning techniques in indoor environments based on stochastic modelling of UWB Round-Trip-Time measurements. IEEE Transactions on Intelligent Transportation Systems, 2016, vol. 17, no. 8, p. 2272-2281. ISSN: 1524-9050. DOI: 10.1109/TITS.2016.2516822

[21] DW1000 USER MANUAL (datasheet). p. 206208. [Online] Cited Version 2.12 Available at: https://www.decawave.com/product-documentation

[22] $N X 2016 A B-38.4 M H Z$ ST4 (datasheet). Available at: http://www.21icsearch.com/datasheet/NX2016AB-38-4MHZST4/ZGtpb2mUYQ==.html

[23] CHUI, C. K., CHEN, G. Kalman Filtering with Real-Time Applications. 4th ed. Springer-Verlag Berlin Heidelberg, 2009. p. 77-96. ISBN: 9783540878483. DOI: 10.1007/978-3-540-87849-0

[24] FOY, W. H. Position-location solutions by Taylor-series estimation. IEEE Transactions on Aerospace and Electronic Systems, 1976, vol. AES-12, no. 2, p. 187-194. ISSN: 00189251. DOI: 10.1109/TAES.1976.308294
[25] PROROK, A., ARIFIRE, A., BAHR, A., et al. Indoor navigation research with the Khepera III mobile robot: An experimental baseline with a case-study on ultra-wideband positioning. In Proceedings of the International Conference on Indoor Positioning and Indoor Navigation (IPIN). Zurich (Switzerland), 2010, p. 1-9. ISBN: 9781424458646. DOI: 10.1109/IPIN.2010.5647880

[26] CETIN, O., et al. An experimental study of high precision TOA based UWB positioning systems. In Proceedings of the IEEE International Conference on Ultra-Wideband (ICUWB). Syracuse (USA), 2012, p. 357-361. ISSN: 21626588. DOI: 10.1109/ICUWB.2012.6340508

[27] SATHYAN, T., HUMPHREY, D., HEDLEY, M. WASP: A system and algorithms for accurate radio localization using lowcost hardware. IEEE Transactions on Systems, Man, and Cybernetics, 2011, vol. 41, no. 2, p. 211-222. ISSN: 1094-6977. DOI: $10.1109 /$ TSMCC.2010.2051027

[28] DE ANELIS, A., DWIVEDI, S., HANDEL, P. Characterization of a flexible UWB sensor for indoor localization. IEEE Transactions on Instrumentation and Measurement, 2013, vol. 62, no. 5, p. 905-913. ISSN: 0018-9456. DOI: 10.1109/TIM.2013.2243501

[29] HE, S., DONG, X. High-accuracy localization platform using asynchronous time difference of arrival technology. IEEE Transactions on Instrumentation and Measurement, 2017, vol. 66, no. 7, p. 1728-1742. ISSN: 0018-9456. DOI: 10.1109/TIM.2017.2666278

[30] CHEN, Y., FRANCISCO, J.A., TRAPPE, W., et al. A practical approach to landmark deployment for indoor localization. In Annual IEEE Communications Society on Sensor and Ad Hoc Communications and Networks (SECON). Reston (USA), 2006, vol. 1, p. 365-373. ISBN: 9781424406265. DOI: $10.1109 /$ SAHCN.2006.288441

\section{About the Authors ...}

Wei WANG received PhD in Navigation, Guidance and Control from Harbin Engineering University, China, 2005. Postdoctoral research associate at Harbin Institute of Technology, China (July 2006 to April 2009). Associate Professor at Harbin Engineering University (August 2008 - August 2010) and Academic Visitor at Loughborough University, UK (January 2010 - December 2010). Professor at Harbin Engineering University (September, 2011 to now). He has published about more than 80 referred journal and conference papers. He is a Senior Member of the Institution of Electrical and Electronic Engineers. His current research interests include Signal Processing for Wireless Navigation Systems and MIMO Radar.

Junjie HUANG received his bachelor degree from Tianjin Chengjian University (TCU) in 2017, Tianjin, China. He is currently working on his Master degree for Navigation, Guidance and Control in the Department of Automation, Harbin Engineering University (HEU). His general research interests lie in the areas of wireless navigation system. 